\title{
Risk Analysis of Electrical Shocks and Fires Through Fuzzy Systems in Electrical Installations
}

\author{
Márcio Mendonça*. Thiago R. Francisco*. Lucas B. de Souza*. Marco A. F. Finocchio* \\ Ivan R. Chrun**. \\ *Federal University of Technology, Paraná, Cornélio Procópio, Brazil; (e-mails: mendonca@utfpr.edu.br; \\ thiagof@alunos.utfpr.edu.br; lucsou@alunos.utfpr.edu.br; mafinoccio@utfpr.edu.br) \\ **Faculty of Engineering and Innovation Technician Professional - FEITEP, Paraná, Maringá, Brazil; (e-email: \\ ivanchrun@gmail.com)
}

\begin{abstract}
The concept of social responsibility in engineering is an obligation of the professional to evaluate their work in the public welfare. Most students do not have contact with real risk situations of electrical instlation shock. In this context, we present an evolution of an extension project work, at the Universidade Tecnológica Federal do Paraná, Cornélio Procópio (UTFPR). Thus, the main goal is to present a tool for the cognitive quantification of electrical shock and fire risks by means of a simplified-Rule-based Dynamic Fuzzy Cognitive Map (sRBD-FCM). To aid training and awareness methods for the inhabiants. It uses historical data from electrical shock and firehazard principles to modify the critical risk levels aspects for fire propagation or increased occurance of electrical shock. Through the initial results it was possible to detect the desirable effects in the proposed cognitive tool. Therefore, future works will address the proposal validation in real case studies. Thus, the historical data will be obtained through periodic visitations in the main risk areas of the city, as the extension project continuation.
\end{abstract}

Keywords: Fuzzy Systems; Electric Shock Hazard; Fire Risk; Risk Quantification.

\section{INTRODUCTION}

Critical safety systems are widely used in sectors such as aerospace, automotive, medical and energy. The systems that fall into this category range from vehicular airbags to propulsion systems in spacecraft. However, they all share one common feature: the occurrence of failures that have the potential to cause harmful effects to human life and the environment. (Kabir and Papadopoulos, 2018).

In the field of electrical energy, specifically in homes, safety is understood as complying with electrical circuit regulations in order to avoid accidents with electric discharges and fires. Security is the focus of this study, as systems become more complex, their prediction through analysis plays a vital role in helping decision-making.

In this sense, different probabilistic methods of risk assessment are used to evaluate the security and reliability aspects of these systems. Fault tree analysis (FTA) is one of the approaches used to estimate these aspects. In fault trees, the inspiration of this research, the logical connections between faults and their causes are represented graphically.

This tool is of a deductive nature: the analysis begins with a top event (system failure) and works toward the leaves of the tree to determine the root causes of the main event. The analysis results shows how different component failures or certain environmental conditions can be combined to cause a system failure (Kabir and Papadopoulos, 2018). An example of an FTA can be seen in Fig. 1. In it, the leaves define final failures according to the decision vocabulary. Its modeling can also be written in the form of rules.

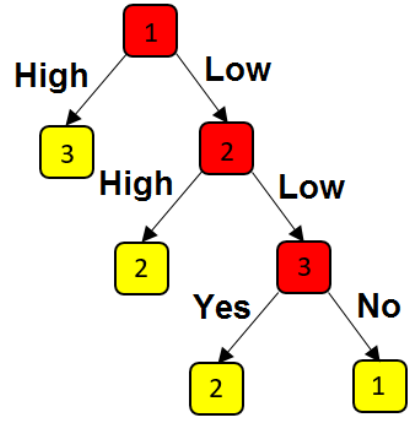

Fig. 1 Example of an FTA.

In the context of work safety, risks can be understood as the possibility of situations that compromise the physical and mental integrity of workers within the work environment (Souza, Barros and Filgueiras, 2017). Thus, in general, risks are considered undesirable events for both employers and employees.

From the identification of the risks, it is necessary to look for measures or tools capable of treating or preventing accidents at work. Factors such as time of exposure and expected severity, in the event of an accident, are able to provide a particular job or activity risk degree(Souza, Barros and Filgueiras, 2017).

It is important to point out that the population, in general, does not have technical knowledge regarding the facilities and their risks. The absence of such knowledge is usually associated with inadequate forms of installation and maintenance. Therefore, this absence requires preventive measures to control the risks. In this context, the awareness and the 
acquisition of basic knowledge by the residents can be effective weapons in the accident's minimization.

Thus, this study uses these foundations in order to propose contributions for the cognitive quantification of fire risks and electric shocks by means of Fuzzy Cognitive Maps (FCMs) in low-income households, from the development of a Simplified Rule-Based Dynamic Fuzzy Cognitive Map.

Specifically, the proposed tool quantifies the risks of electric shocks and fires through the qualitative experience of the students in the extension project "Analysis and correction of electrical installations in low-income housing in the city of Cornélio Procópio", held at Universidade Tecnológica Federal do Paraná. In addition, this proposal uses historical data on the occurrence of accidents related to electric shocks, as well as fire harzards.

As a result, there is an increase or decrease of risk levels, considered critical for the propagation of fires or accidents caused by electric discharges. Analogously, if these facts do not occur, the intensity of the corresponding causal relationships is modified in a proportional manner to the occurrence of the mentioned topics, thus changing the levels of risk presented.

\subsection{Motivations and the extension project}

This work was motivated by recent events, such as the Fire in the Wilton Paes de Almeida Building, in São Paulo, in May, (Fig. 2) (Darlington, 2018).. In addition, data from the United Nations (UN) indicate that $28 \%$ of the Brazilian population (52 million) lived in favelas in 2005 . Thus, the way of organizing and constructing this type of housing is a critical factor in the metropolises with regard to the risk of fire (Alves, 2014). Thus, we aim to help in the decision making in order to prevent such disasters

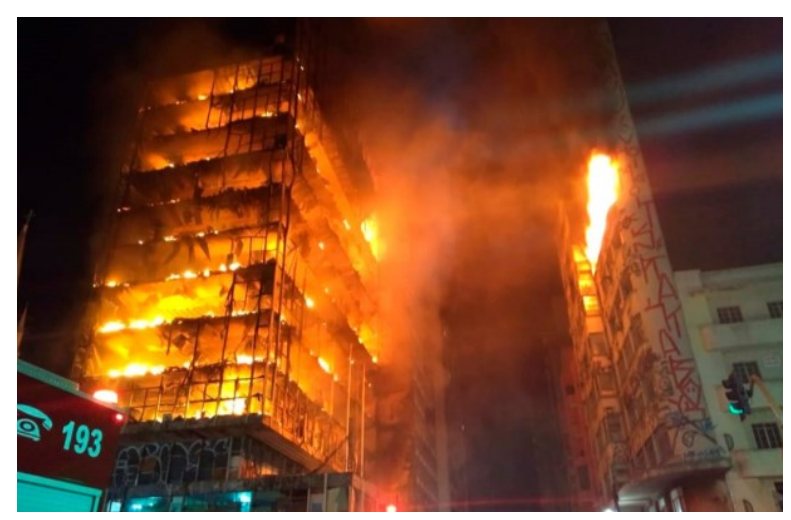

Fig. 2 Fire in the Wilton Paes de Almeida Building.

Such data and incidents point to the need for studies that may contribute to their minimization. In the literature, one can find works such as (Alves, 2014), (Pereira and González, 2013) e (Bruno, 2010), which analyze risk prevention programs, safety conditions for low-income housing, and the awareness of residents. Especially in low-income families housing, the causes are usually related to the inadequate forms of installation and how they are used.

In this work, the situations analyzed were taken from an extension project and a monograph, both carried out at Federal
Technological University of Paraná, Cornélio Procópio. Which documentation can be found at (Mendonça et al., 2018).

In short, the project aims to contribute to the safety and wellbeing of society, especially low-income communities that generally need guidance and / or improvements in the electrical installations of their homes. In addition to contributing to the quality of life improvement and safety of risk groups, in parallel the project provides the engineering student with an immersion in the problems of daily life through families' visitation, enabling the relationship between scientific technical knowledge and its applications in a context of society. Fig. 3 shows an example of the situations encountered by the students.

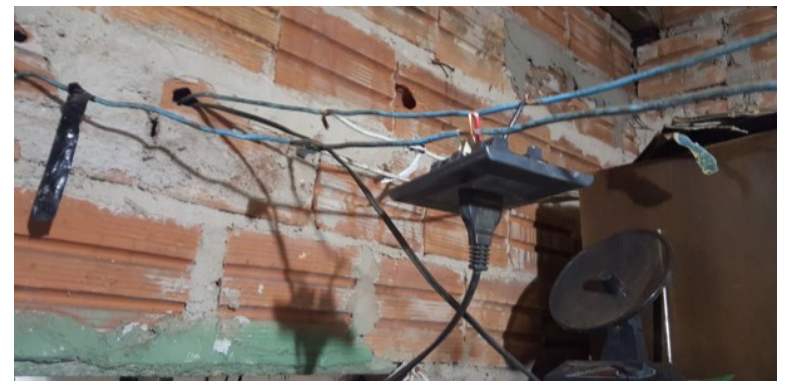

Fig. 3 Example of precarious electrical installations found.

The paper is organized as follows. Section II presents the concepts of electric shock, and the contextualisation of the sRBD-FCM proposed by means of national norms and regulamentation. Section III presents the results obtained by the FCM according to the situations found. Finally, Section IV concludes the work and addresses evolutions in the tool.

\section{APPROACHES AND FUNDAMENTALS}

It can be affirmed that the probability of failure of a relatively new component and with insufficient historical data of failures could, in theory, be estimated based on experts knowledge (Kabir and Papadopoulos, 2018). Consequently, a system security and reliability can be evaluated on the basis of generic statistical data, which can be obtained from existing reliability databases (Mazzuto et al., 2018). However, the use of this generic data adds more uncertain parameters and imprecision to the analysis results. It is in this context that the use of fuzzy logic, and especially the FCMs, allows to incorporate uncertainties in the analysis.

\subsection{Electrical shocks}

The electric shock is one of the electrical concepts employed in this work. Some definitions according to Regulatory Norm NR 10 and NBR 5410 were previously presented. However, it is possible to highlight the consequences of electrical shock in humans, as well as the possible occurrence of fires. It is observed that, the fire hazard analysis it is not the scope of this work, due the need to consult local norms and fire load survey data.

The passage of electric current through the human body makes it part of an energized circuit and the electric shock causes various physiological and pathological damages to the body. The effects of electric shock on the body depend on some 
factors, such as the intensity of the electric current that circulates in the body, the value of the electrical voltage, the contact area, the humidity present on the contact surface, current path and the electrical resistance of the human body.

The contact point subjected to electric shock defines the course of electric current in the body and consequently its severity. The physiological reactions range from tingling sensationto death, either by cardiorespiratory arrest, asphyxia, or by burns from explosions, in the case of electric arcs. According to data from the Brazilian Association for Awareness of the Electricity Dangers (Abracopel), 1222 accidents involving electricity were recorded in 2015, 8.1\% more than in 2014 (Abracopel, 2018).

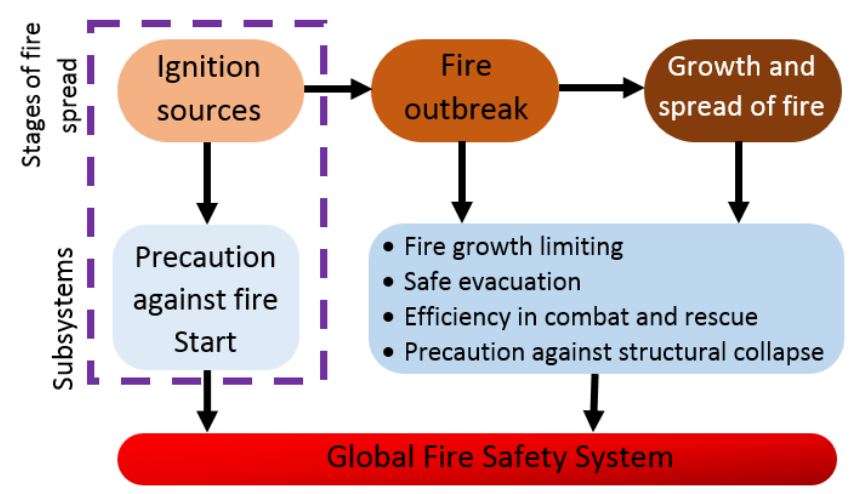

Fig. 4. Flowchart for fire prevention and fire fighting.

Simplistically, it is possible to define the operation area of this work as part of a global fire safety system, shown in Fig. 4 (Alves, 2014). Thus, the proposed sRBD-FCM mainly assists in the precaution measures against the beginning of the fire, quantifying the possible risks of electric shock and fire according to the relations established by experts.

We can find the relation between the concepts proposed for the sRBD-FCM and some normative in the country. In this sense, some of the Brazilian standards that guide preventive action are NBR 5410 (2008), for electrical installations, NBR 15219 (2005), for fire prevention, and the Technical Procedure Norms (NPTs) for the Fire Department.

In these regulations, aspects relevant to the development of the MHR were identified: fire risk (mild, moderate or high); precariousness of electrical installations (factors that represent a risk of short circuit and electric shock). In addition, lack of adequate lighting (increased handling of candles increases the risk of fire); presence of protective circuits, incorrect sizing of wiring and lack of grounding (risk of electric overload and shock). Finally, the structural precariousness of the dwellings was also considered, which increases the risks for repairs due to the fragility of the materials used ('Comando do Corpo de Bombeiros', 2012, 2014a, 2014b).

The Fig. 5 shows a diagram with the main areas of knowledge involved for the development of the proposed tool. In short, concepts of safety engineering, specifically, risk analysis, and regulations have gained prominence. Concepts of social engineering for interaction with low-income communities. Finally, concepts of Fuzzy Cognitive Maps, for development of the cognitive tool.

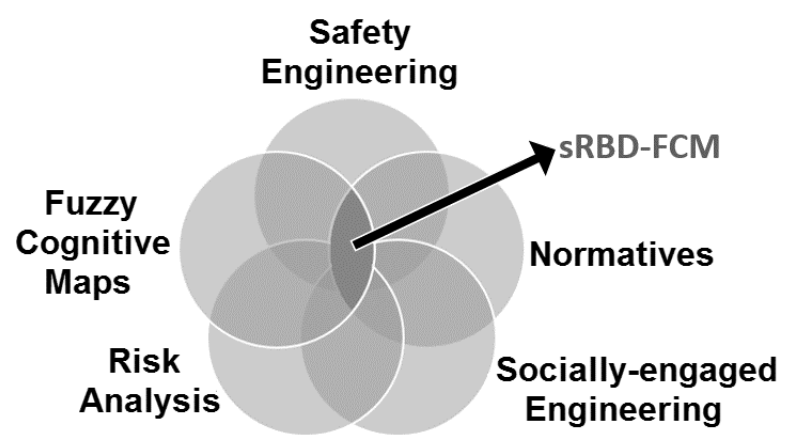

Fig. 5 Approaches used for the construction of sRBD-FCM.

\subsection{Fuzzy Cognitive Maps}

In 1948, Tolman (1948) used cognitive maps describinghe the memorizing behavior of rats. Subsequently, the technique was employed by Axelrod (1976), as a binary tool in decision theory applied to political-economic problems. Posteriorly, Kosko (1986) would add the fuzzy logic to these graphs, thus creating the FCMs in 1986.

The variables of an FCM symbolize the linguistic concepts connected to other concepts through fuzzy connections. These connections model the relationships between concepts by means of causality levels(weights)(Kosko, 1986). The FCM formal representation adopted in this work (Pedrycz et al., $2005)$ is in the format of the tuple $(\mathrm{C}, \mathrm{W}, \mathrm{S}, \mathrm{f})$, for intervals of $\mathrm{K}=[-1,1]$ and $\mathrm{L}=[0,1]$ (Nápoles, Bello and Vanhoof, 2013):

(i) $C=\left\{C 1, C 2, \ldots, C_{n}\right\}$ : set of n FCM concepts;

(ii) $W:\left(C_{i}, C_{j f}\right) \rightarrow w_{i j}$ is the weight that link the concepts of input and output. $w_{i j}$ represents a causal relation. Respectively, $w_{i j}<0$ and $w_{i j}>0$ indicate a negative and positive causal relationship. $\left\|w_{i j}\right\|$ is the intensity of the causal relationship. With this, $W(C x C)=\left(w_{i, j}\right) \in K^{n x n}$ is the connection matrix;

(iii) $S: C_{i} \rightarrow S_{i}$ is the degree of activation of a concept, where: $S(0)$ is the initial vector that specifies values of all concept nodes; $S(t) \in L^{n}$ is a state vector at iteration t;

(iv) $f: R \rightarrow L_{i}$ is a decision function, which includes recurrent relationship at $t \geq 0$ between $S(t+1)$ and $S(t)$. The decision-making or inference function of the FCM per node is defined by $f$ :

$f\left(x_{i}\right)=f_{c}\left(\sum_{j=1}^{n} w_{i j} * x_{j}\right)$

$f_{c}(u)=\frac{1}{1+e^{-\lambda u}}$

In (1) e (2), $f_{c}$ is the activation function of the concept, $x_{j}$ is the value of the concept $j . w_{i j}$ represents the causal relationship between the concepts $i$ and $j$, and $\lambda$ is the learning rate (1).

As a consequence of their use, the FCMs were divided into extensions that improve or overcome their drawbacks, such as rule-based knowledge representation (Papageorgiou, 2014). In this work, we present a summary of the Dynamic Fuzzy Cognitive Maps (D-FCM), used as basis of our proposal. A model of D-FCM is seen in (Mendonça et al., 2013) for the supervision of a chemical process. This extension is based on the Timed Automata-Based Fuzzy Cognitive Maps (TAFCM), proposed by (Acampora and Loia, 2011). 
The development of a D-FCM begins with the construction of a classic FCM. Thus, through the dynamic configuration of the causal relations forces it is possible to model dynamic systems, similar to the TAFCM approach (Mendonça, 2011; Mendonça et al., 2013). However, as shown in (Papageorgiou and Salmeron, 2013; Felix et al., 2017) there are about fifteen extensions of FCM in the literature. Its applications are within the fields of artificial life, agriculture, medical care, control, games and robotics (Papageorgiou and Salmeron, 2013).

For this work, a FCM with nine concepts was developed. The causal relations, weights and influences (positive or negative), as well as the concepts themselves, were defined according to the aspects observed with the dwelling visitation. It should be noted that the initial value for all concepts was zero. Fig. 6 shows the structure of a similar fuzzy system to assist its understanding of the proposed tool.

Table 1. FCM Proposed Concepts

\begin{tabular}{|c|c|}
\hline Concept & Description \\
\hline C1 & Fire risk - occurrence of self causal relationship \\
\hline C2 & $\begin{array}{c}\text { Risk of electric shock - occurrence of self causal } \\
\text { relationship }\end{array}$ \\
\hline C3 & Precarious electrical installations \\
\hline C4 & Correct dimensioning of protection circuits \\
\hline C5 & Lack of rounding \\
\hline C6 & Housing Structural precariousness \\
\hline C7 & Presence of fuel \\
\hline C8 & Inadequate lighting in the habitations \\
\hline C9 & Electrical wiring correct dimensioning \\
\hline
\end{tabular}

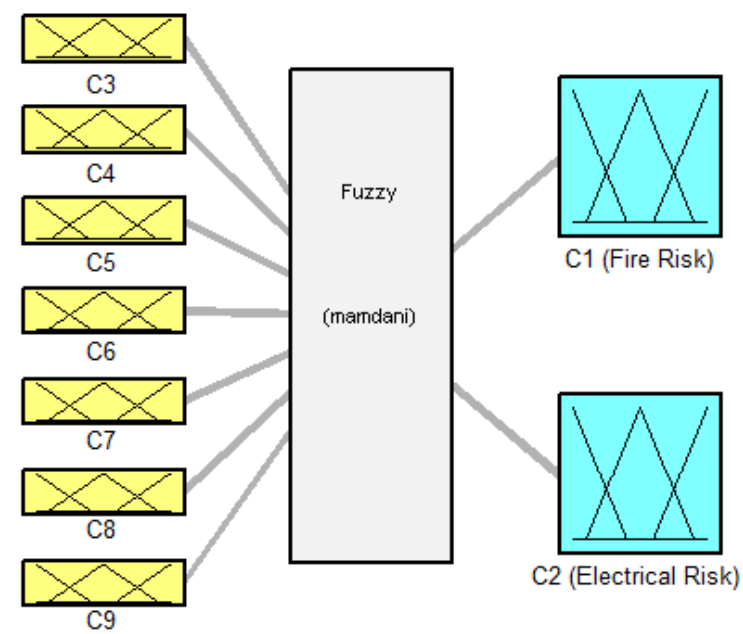

Fig. 6 Structure of a Mamdani fuzzy system.

In this context, levels (notes) were given from zero to ten for each of relationships, normalized in [0 1] for its insertion in the FCM. Fig. 8 shows the description of the concepts in Table 1, the initial version corresponding to the classic FCM in Fig. 7 and the sRBD-FCM proposed in Fig. 8. The self-causal relations are of selection (represented by a diamond), trigerring when an event occurs or not within the predefined period of six months, for example.

In this sense, it is possible to include historical data as a possible change in the cognitive model initially proposed by the empirical knowledge of specialists. The levels of causality between the concepts can be seen in Figs. 6 and 7 respectively for classical (conventional) FCM and its evolution through the proposed tool (sRBD-FCM).

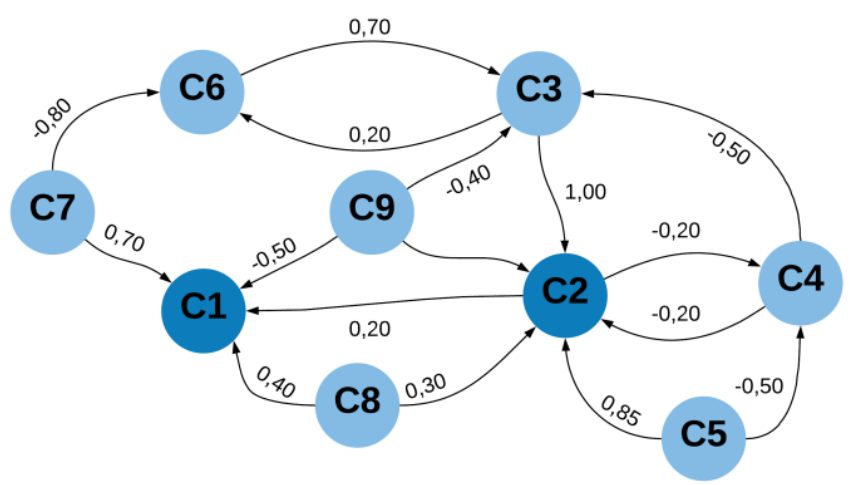

Fig. 7 Classic FCM.

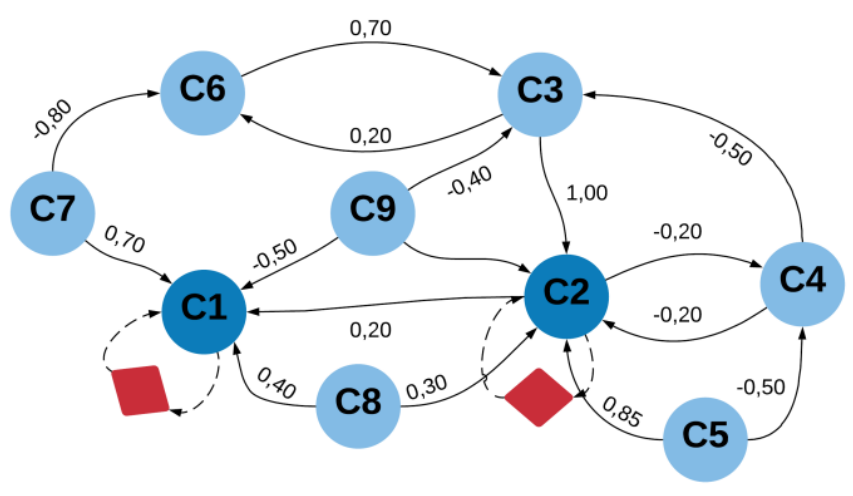

Fig. 8 sRBD-FCM proposed.

The causal relationships were developed through the observation of possible occurrences due to the precariousness of the facilities. As examples, the need of lit candle and its related risk of fire, and the presence of bare wires or poorly made extensions, are possible ocourrances of electric shocks.

In this work, sRBD-FCM is based on empirical knowledge and experts, plus historical data obtained through questions to residents of residences at possible risk. Thus, the selection relationship changes the value of concepts $\mathrm{C} 1$ and $\mathrm{C} 2$ selfinfluence according to rules and with the occurrence or not of the cited events. The rules used are as follows:

(i) If an electric shock occurs, the occurrence of a positive selfcausal relationship between the concept $C_{l}$ with $\mathrm{W}_{11}$ is triggered;

(ii) If a fire occurs, it triggers the occurrence of a positive selfcausal relationship between the concept $C_{2}$ with $\mathrm{W}_{22}$;

(iii) If electric shock does not occur, it triggers the occurrence of a negative self-causal relationship between the concept $C_{I}$ with $\mathrm{W}_{11}$;

(iv) If fire does not occur, it triggers the occurrence of a negative self-causal relationship between the concept $C_{2}$ with $\mathrm{W}_{22}$.

A priori, the value of the self-causal relations weights will have their values at 0.5 and can adjust the intensity of the the self-causal relation influence according to the experience acquired with the occurrences historial data. However, they 
might be an adjustment or refinement variable of the causal model. The ontology for the sRBD-FCM development can be found in Table 2, based on the design of a D-FCM (Mendonça and Arruda, 2015).

The selection concept of was based on the thesis (Mendonça, 2011), in which a proposed extension of FCM denominate Dynamical Cognitive Networks (DCN), (Mendonça and Arruda, 2015) employing new concepts and relations in the classic Kosko model, as the selection relationship used in this work.

It should be noted that the ontology of Table 2 may change slightly depending on the type of problem to be modeled (control supervisory systems, robotics, virtual world, diagnostics, decision-making, smart cities, among others). In addition, the algorithms used in each phase may be different and essentially complementary.

Consequently, abstraction of the necessary knowledge to perform these steps is not a trivial task, and as the initial steps, any relevant information about the behavior of the system is not to be considered, as it may affect the other steps of the sRBD-FCM construction. It is observed that steps 5 and 6 are more meaningful for control applications, for example, in which the cognitive model must be refined dynamically. After the construction step, we highlight the validation step, in which the belief system must be the most faithful to the physical system or real system modeled.

Table 2. Ontology Creation of a sRBD-FCM

\begin{tabular}{|c|c|}
\hline Stage & Description \\
\hline 1 & $\begin{array}{l}\text { Identification of the concepts, functions used, } \\
\text { their correlations and causal nature (positive, } \\
\text { negative or neutral). }\end{array}$ \\
\hline 2 & $\begin{array}{l}\text { Initial definition of causal concepts and } \\
\text { relationships. The initial values for both can be } \\
\text { determined by expert knowledge, system } \\
\text { behavior simulations and, in this case, } \\
\text { historical data analysis. }\end{array}$ \\
\hline 3 & $\begin{array}{l}\text { Determination of the semantic influence } \\
\text { between concepts. Conception of the different } \\
\text { points of view of the system. }\end{array}$ \\
\hline 4 & $\begin{array}{l}\text { Determination of the semantic influence } \\
\text { between concepts. Conception of the different } \\
\text { points of view of the system. }\end{array}$ \\
\hline 5 & $\begin{array}{l}\text { Information processing, adaptation and tuning } \\
\text { of the D-FCM model, adjusting its responses to } \\
\text { desired output values. If necessary, a machine } \\
\text { training method (Reinforcement Learning, } \\
\text { Hebb Learning, Evolutionary Algorithms, etc.) } \\
\text { can be used to dynamically tune the model. }\end{array}$ \\
\hline 6 & $\begin{array}{l}\text { The modeling of the management level } \\
\text { corresponding to the rules base development } \\
\text { associated with the concepts of factors and } \\
\text { selection relationships; and, the } \\
\text { implementation of the online learning } \\
\text { algorithm (if necessary). }\end{array}$ \\
\hline 7 & $\begin{array}{l}\text { Test and validation of the proposed model by } \\
\text { obtaining data from the continuity of the } \\
\text { extension project. }\end{array}$ \\
\hline
\end{tabular}

\section{INITIAL RESULTS}

The proposed toll and its results are still in an initial state, howeverit was possible to identify different levels of fire risk and electric shock in different situations, or in different habitations analyzed. Fig. 9 shows the evolution of sRBDFCM without record of occurrence of no electric shock or fire principle. An occurrence entry over the observed period shows an increase in the risk level.

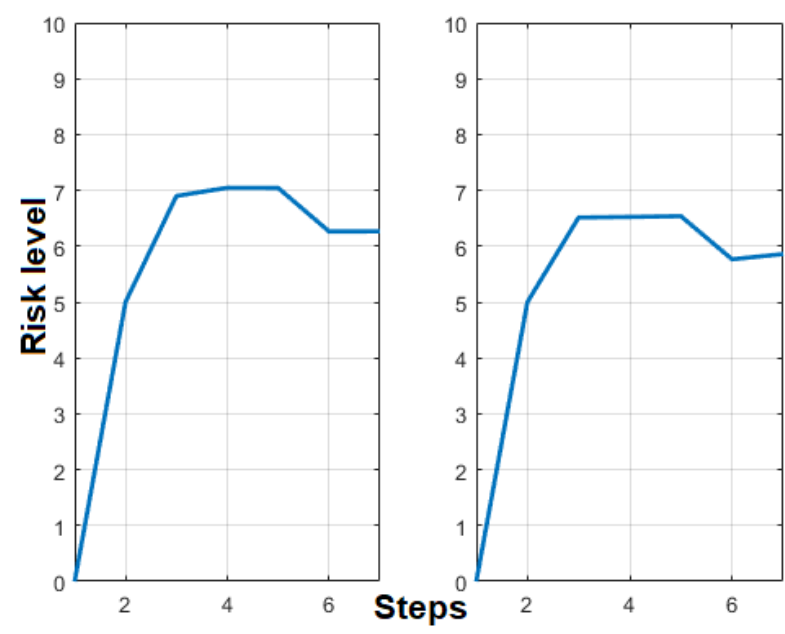

Fig. 9 Without the occurrence of any record of fires and electrical shocks.

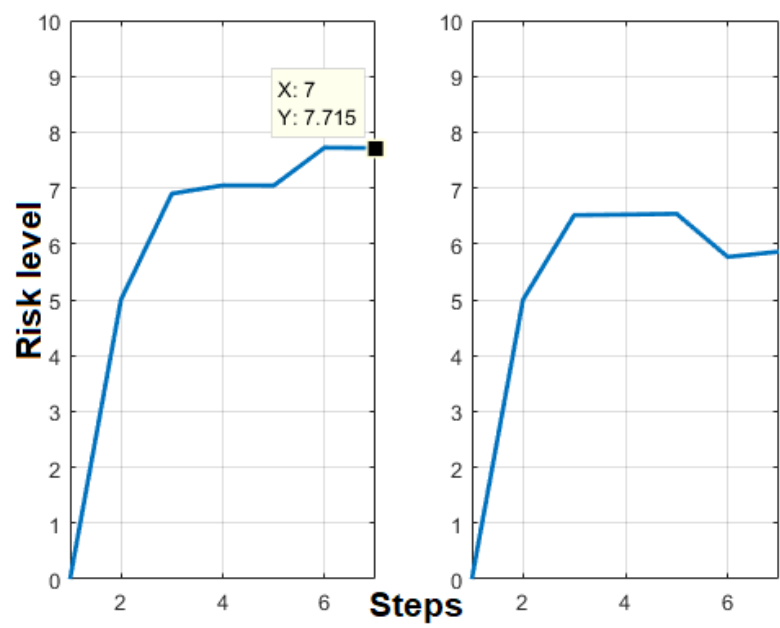

Fig. 10 Occurrence of fire principle, but without occurrence of any record shock.

The input of the entries is done by means of binary questions in the software of development, confering the risk level of shock and occurrence of fires, 6,25 and 5,86respectively. It is observed that these results consider the habitations in the same conditions, differentiating a priori only entry occurrence. Figure 10 shows the results of fire levels with the occurrence of fire and without the presence of shock risk.

It is noteworthy that five cycles were sufficient to reach the FCM limit cycle. An initial empirical calculation is to identify how many internal loops, and use that number of loops as an initial hypothesis of number steps in the algorithm. Graphically it is possible to see the results reach the limit cycle with five steps, and in the sixth and seventh they trigger 
according to the occurrence or not of the fire and / or electric shocks entries. .

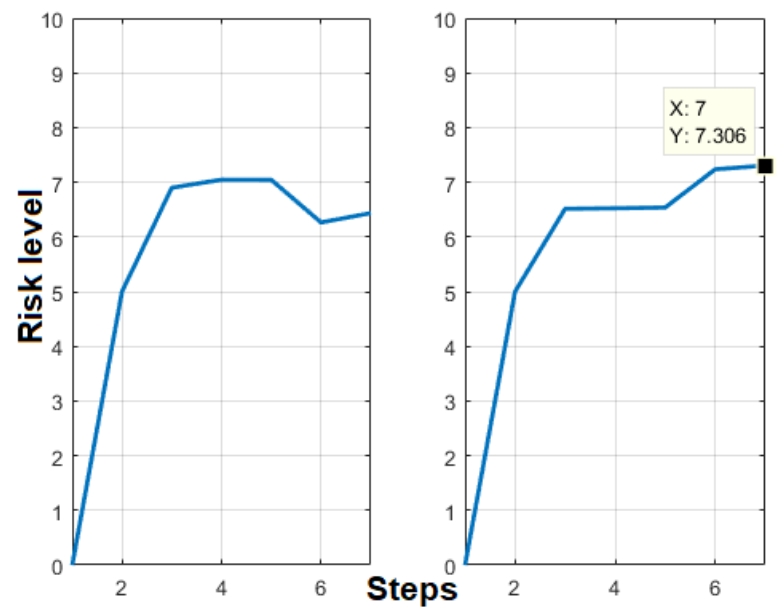

Fig. 11 Occurrence of electric shock, but without occurrence of any occurrence entry of fire or principle.

The results show that an occurrence entry increases the level of risk for an upcoming analysis, and in particular, were able to compare in a relative way for each residence, aiming possible corrections through pedagogical tools such as lectures.

\section{CONCLUSIONS}

Although the results are initial, it is hoped to have contributed to the area of risk analysis of safety engineering. A quantitative value can be observed for the occurrence level of fires and electric shocks according to relevant variables extracted from expert opinions in different scenarios.

In addition to the contributions to the area of risk analysis, it is also expected to have contributed with an initial version of a possible extension of FMC theory with a cognitive model that allows inferring by means of occurrences historical data. In a reduced way, it was possible to include historical factors in the results of fire and electric shock hazards.

Future studies include the validation of a proposal to include a occurrences history through periodic visits to the areas covered and similar ones. Finally, to use as a tool for training and awareness of inhabitants of risk areas and professionals in the area, such as fire brigades. Another possible contribution related to the application of FCMs in electric energy will be the development of a tool based on the consumers' behavior to predict electric charges.

\section{ACKNOWLEDGEMENTS}

The authors gratefully acknowledge the financial support for this research from CAPES/BRASIL (Process 88887.354058/2019-00), Federal University of Technology Paraná, Cornélio Procópio (UTFPR), the Araucaria Foundation, the Secretary of State for Science, Technology and Higher Education (SETI-PR) and the Government of the State of Paraná for the financial support.

\section{REFERENCES}

ABNT (2008). NBR-5410. Instalações elétricas de baixa tensão. Rio de Janeiro, Brasil.
Abracopel . (2018). Anuário Completo de Dados de Acidentes de Origem Elétrica de 2013 a 2017. Available at: http://abracopel.org/estatisticas/ (Accessed: 1 October 2018).

Acampora, G. and Loia, V. (2011). 'On the temporal granularity in fuzzy cognitive maps'. IEEE Transactions on Fuzzy Systems, 19(6), pp. 1040-1057.

Alves, L. A. (2014). Análise dos Programas de Segurança Contra Incêndio em Favelas na Cidade de São Paulo. Instituto de Pesquisas Tecnológicas do Estado de São Paulo.

Axelrod, R. (1976). Structure of Decision: The Cognitive Maps of Political Elites. Princeton, NJ, USA: Princeton Univ. Press.

Bruno, A. P. (2010). 'Método de Análise de Risco de Incêndios em Favelas: uma Abordagem', Territorium Revista da Associação Portuquesa de Riscos, Prevenção e Segurança, 17, pp. 119-126.

'Comando do Corpo de Bombeiros'. (2012). NPT 007 Separação entre edificações (Isolamento de riscos), 2, pp. 1-15.

'Comando do Corpo de Bombeiros'. (2014b). NPT 010 Controle de materiais de acabamento e de revestimento, 3.

'Comando do Corpo de Bombeiros' . (2014a). NPT 014 Carga de incêndio nas edificações e áreas de risco, 3 , pp. $1-15$.

Darlington, S. (2018). Fire in São Paulo, Brazil, Brings Down a High-Rise Building, The New York Times. Available at: https:/www.nytimes.com/2018/05/01/world/americas/s ao-paulo-brazil-fire-collapse.html (Accessed: 15 April 2019).

Felix, G. et al. (2017). 'A review on methods and software for fuzzy cognitive maps', Artificial Intelligence Review, (March 2018), pp. 1-31.

Kabir, S. and Papadopoulos, Y. (2018). 'A review of applications of fuzzy sets to safety and reliability engineering', International Journal of Approximate Reasoning. Elsevier, 100, pp. 29-55.

Kosko, B. (1986). 'Fuzzy cognitive maps'. International Journal of Man-Machine Studies, 24(1), pp. 65-75.

Mazzuto, G. et al. (2018). 'Fuzzy Cognitive Maps designing through large dataset and experts' knowledge balancing'. In 2018 IEEE International Conference on Fuzzy Systems (FUZZ-IEEE). Rio de Janeiro, BR: IEEE, pp. 16.

Mendonça, M. (2011). A Contribution to Intelligent System Modeling based on Dynamic Cognitive Networks. Federal University of Technology, Paraná, Curitiba.

Mendonça, M. et al. (2013). 'A dynamic fuzzy cognitive map applied to chemical process supervision'. Engineering Applications of Artificial Intelligence, 26(4), pp. 11991210. 
Mendonça, M. et al. (2018). 'Análise e atenuação de riscos em instalações elétricas em moradias de baixa renda na cidade de cornélio procópio'. In XLVI, Congresso Brasileiro de Educação em Engenharia e $1^{\circ}$ Simpósio Internacional de Educação em Engenharia. Salvador, BR: ABENGE, pp. 1-10.

Mendonça, M. and Arruda, L. V. R. (2015). A Contribution to the Intelligent Systems Development Using DCN. 1st edn. Riga, Latvia: Scholars Press.

Nápoles, G., Bello, R. and Vanhoof, K. (2013). 'Learning Stability Features on Sigmoid Fuzzy Cognitive Maps through a Swarm Intelligence Approach'. In RuizShulcloper, J. and Sanniti di Baja, G. (eds) CIARP 2013: Progress in Pattern Recognition, Image Analysis, Computer Vision, and Applications. Lecture Notes in Computer Science, vol 8258. Berlin: Springer Berlin Heidelberg, pp. 270-277.

NBR 15219 - Plano de Emergência Contra Incêndio (2005). 'Associação Brasileira de Normas Técnicas', pp. 1-13.

Papageorgiou, E. I. (ed.). (2014). Fuzzy Cognitive Maps for Applied Sciences and Engineering. Heidelberg: Springer-Verlag Berlin Heidelberg.

Papageorgiou, E. I. and Salmeron, J. L. (2013). 'A review of fuzzy cognitive maps research during the last decade'. IEEE Transactions on Fuzzy Systems, 21(1), pp. 66-79.

Pedrycz, W. et al. (2005). 'Genetic learning of fuzzy cognitive maps'. Fuzzy Sets and Systems, 153(3), pp. 371-401.

Pereira, A. G. and González, M. L. (2013). ‘Segurança Contra Incêndios em Edificações de Interesse Social: Estudo de Caso'. Revista Brasileira de Estudos de Segurança Pública (REBESP), pp. 43-46.

Souza, I. F. de, Barros, L. de A. and Filgueiras, V. A. (eds). (2017). Saúde e Segurança do Trabalho: Curso Prático. 1st edn. Brasília, Brasil: ESMPU.

Tolman, E. C. (1948). 'Cognitive maps in rats and men'. Psychological Review, 55(4), pp. 189-208. 